\title{
Partial Replacement of Durum Wheat Flour with the Blend of Non-traditional Cereals and Legume Flour on Pasta Quality: Review
}

\author{
Tamirat Kore \\ DebreZeit Agriculture Research Center, Ethiopian Institute of Agricultural Research, \\ Bishoftu, Ethiopia. P.O. Box: 32
}

\begin{abstract}
Durum wheat semolina is the only raw material of choice for high quality pasta products. Still the products have lower nutrient quality (protein, vitamins and minerals), high glycaemic response and high gluten allergenicity effect. In addition to durum wheat low yield capacity, it leads the shortage of supply due to low durum wheat local production in developing countries. The aim of this review to assess the replacement of durum wheat with better nutritional quality and locally available cereals and legumes for producing pasta with good nutritional, sensorial, cooking and textural quality. Development of legume fortified pasta products enhance the nutritional characteristics of processed products in terms of protein, dietary fiber and micro-nutrients. In addition, the inclusion of legume flour, as ingredients in pasta products which have lowering glycaemic indices (GI) and allergenicity compared with semolina pasta. Gluten-free spaghetti (unripe plantain, chickpea and maize flours) were similar diameters, water absorption values and overall sensorial acceptability but higher hardness, cohesiveness and chewiness than the control. It can be concluded that nutritional value of pasta can be improved by optimum level of legume and cereals incorporation without any significant effect on cooking, textural and sensorial quality.
\end{abstract}

Keywords: Durum wheat, Milling, Legume, Pasta product, Quality

DOI: $10.7176 /$ FSQM/107-04

Publication date: April $30^{\text {th }} 2021$

\section{Introduction}

Pasta is the most ancient and widely consumed food products in many regions around the world. Pasta has generally described paste products fitting the Italian style of extruded foods such as spaghetti or lasagna, and is usually distinguished from the oriental style of sheeted and cut foods called 'noodles', which are commonly made from wheat (Dick and Matsuo, 1988). The main ingredients used to make pasta are durum wheat semolina and water.

Pasta products have more than 600 diverse shapes which depend on the shape of die that encompasses mainly into four: short pasta (elbow macaroni, rigatoni, fusilli, shells); long pasta (spaghetti, linguine, vermicelli); egg noodles (pasta made with egg) and specialty items (lasagna, manicotti, jumbo shells, and stuffed pasta). Spaghetti is in the form of solid rods, elbow macaroni, lasagna, shells, and various noodle shapes are among the most popular shapes (Dick and Matsuo, 1988).

Pasta products are appreciated by consumers due to its cheap cost, widely available products, easiness to prepare, versatility, good sensory attributes, long shelf life and easy to transport (Pagini, 1986; Feillet and Dexter, 1996); thus is a quick food option for most people around the globe (Melissa, 2014). Pasta is a well-liked food product in many cultures, consumed by all age groups. Therefore, it is considered as a good vehicle to improve the nutritive values of the diet of developing countries.

\section{Nutritional composition of pasta}

In average pasta products have high energy value (350kcal per $100 \mathrm{~g})$, protein content $(11-12) \%$ and has rapid digestibility. The mineral content of pasta products is unbalanced with a marked high prevalence of potassium and phosphorus but low in iron and zinc content (Ferrari and Piazza, 2006; USDA, 2016). In general, pasta contains most significant quantities of complex carbohydrates; while its protein content is lower (Douglass and Matthews, 1988; Starta, 2004). The protein in pasta contains six of the eight essential amino acids lacking lysine and threonine; inadequate amount of vital minerals and vitamins. 
Table 1: Average nutritional composition of dried pasta products

\begin{tabular}{|c|c|c|c|c|c|c|c|c|c|c|c|c|c|c|}
\hline \multirow[b]{2}{*}{ Composition } & \multicolumn{6}{|c|}{ Proximate composition $(\mathrm{g})$} & & \multicolumn{5}{|c|}{ Mineral content (mg) } & \multicolumn{2}{|c|}{$\begin{array}{l}\text { Vitamin } \\
(\mathrm{mg})\end{array}$} \\
\hline & 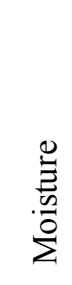 & $\begin{array}{l}\frac{\Xi}{0} \\
\frac{\Xi}{0} \\
0\end{array}$ & $\frac{\sqrt[n]{0}}{\stackrel{3}{a}}$ & 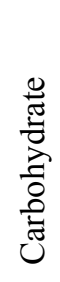 & 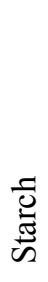 & 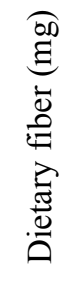 & 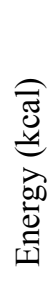 & 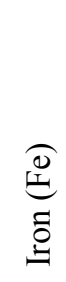 & 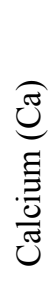 & 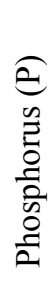 & 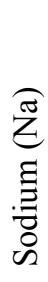 & 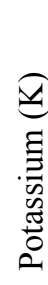 & 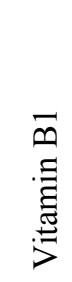 & 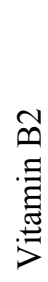 \\
\hline $\begin{array}{l}\text { Content per } \\
(100 \mathrm{~g})\end{array}$ & 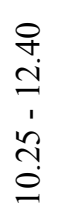 & 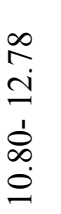 & $\begin{array}{l}\hat{0} \\
0 \\
0 \\
1 \\
0 \\
0\end{array}$ & 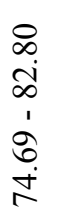 & ָั & 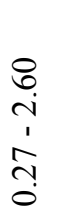 & $\begin{array}{l}8 \\
\dot{0} \\
m \\
m\end{array}$ & $\stackrel{\text { n̊ }}{-}$ & 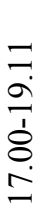 & 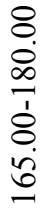 & $\begin{array}{l}8 \\
8 \\
0 \\
1 \\
8 \\
\text { in }\end{array}$ & $\begin{array}{l}n \\
\hat{\sigma} \\
1 \\
8 \\
8 \\
8 \\
0\end{array}$ & $\begin{array}{l}\infty \\
\stackrel{0}{0} \\
\dot{1} \\
\dot{0}\end{array}$ & $\begin{array}{l}0 \\
\stackrel{0}{0} \\
\dot{1} \\
= \\
\end{array}$ \\
\hline
\end{tabular}

Source: (Drake et al., 1989; Ferrari and Piazza, 2006)

The main ingredients used to make pasta are durum wheat semolina and water. The summary of durum wheat agronomic, composition and other related facts are discussed below.

\section{Durum wheat}

Generally, wheat is mainly classified into bread wheat and durum wheat. Bread wheat (Triticum aestivum) is common wheat and the most cultivated crop taking a share up to $95 \%$ (Fuad and Prabhasankar, 2010). It is mainly used for making white bread, noodles, all-purpose flour, doughnut and crackers. This is because it contains lower protein and has lower hardness compared with durum wheat.

Durum wheat (Triticum durum) is the most suitable raw material for the production of pasta products because of its hardest endosperm textures, larger and more vitreous kernel, and its endosperm contains high xanthophylls or luteins (not carotene) pigments which amounts twice the concentration in bread wheat.(Liu et al., 1996). It is estimated that around 50 percent of world durum wheat production is converted into pasta products such as spaghetti, macaroni, vermicelli, etc. The remaining is used for some other regional foods like puffed cereals, hot cereals, desserts, flat bread, leavened bread, and noodles. Additionally, pasta made from durum wheat cultivars of superior quality gives a bright yellow colour and after cooking it retains the required firmness and do not have stickiness (Barrelli et al., 1999).

The nutritional content comparison of durum wheat (semolina) and common wheat (farina) flours contain the percentage of protein $(12.70,10.60)$; damaged starch $(11.50,8.50)$; carbohydrate $(77.80,82.00)$; amylose $(27.00$, 23.00); lipids (1.00, 0.50) and dietary fiber (1.19, 0.91), respectively (USDA, 2016; Steglich, 2013).

The three main distinct parts of durum wheat kernel are the bran, the starchy endosperm and the germ. During milling a product with bright yellow colour, a low speck count and uniform granulation called semolina is produced mainly from the endosperm. The bran and the germ are often removed. The bran layers are high in cellulose and hemicelluloses, and minerals. The germ is rich in protein, lipids, sugar, and ash constituents.

\section{Durum wheat milling process}

The durum wheat milling process has the following step: cleaning, conditioning, de-braning, milling process (Breaker, Reduction and Purification) (Dexter and Marchylo, 2000).

Cleaning removes large impurities and the very small and lightweight impurities, such as fine dust, insect fragments and eggs, various types of dirt particles, etc.

The second process is conditioning. Durum wheat is tempered prior to milling to toughen the bran, thereby reducing the number of bran specks in the semolina. The temper time is short in order to retain the hard, vitreous nature of durum wheat thereby, maximizing the release of large endosperm particles and minimizing the yield of flour (Kruger et al., 1996).

De-braning or scourer is the next milling process step for maximizing extraction rate, or compromising on flour quality without sacrificing semolina refinement. De-braning also removes the surface discoloration of durum 
wheat kernels and greatly enhancing the appearance of semolina from lower grade durum and 5\% yield advantage over traditional semolina milling at comparable ash and colour (Dexter et al., 1994).

The Milling process continues after de-braning and it contains: breaker, reduction and purification. The break system is the first step for durum wheat milling process and it allows the gradual release of coarse endosperm particles with a minimum yield of flour. Passage through the rolling mills is alternated with sifting phases carried out by the plan sifters and the purifiers. The next step is a reduction process that helps to produce with semolina with finer granulation. Past studies showed negative relation between pasta quality and the size of semolina because reducing semolina greatly increases starch damage (Dexter and Marchylo, 2000). Damage of starches exposes them to enzymatic activity that causes the formation of reducing sugars that, in turn, are very harmful to the pasta. When low temperature drying is used in pasta making, this result in higher loss of solids during cooking and high surface break down, leading to stickiness (Matsue and Dexter, 1980)

\section{Durum wheat replacement with non-traditional ingredient}

Pasta produced from durum wheat semolina lacks some essential amino acids like lysine and threonine, poor in fibres, low mineral and vitamin contents. Thus, it is getting less preferred by health conscious consumers (Jayasena and Nasar-Abbas, 2011). The need for gluten-free (GF) products is currently increasing as the demanding group extends from celiac disease patients to people looking for non-allergenic ingredients like gluten which is abundantly found in durum wheat (Guarda et al., 2004).

In Sub-Saharan African diet, the main energy sources are cereals which are adequate in methionine and cysteine and B vitamins but limited in lysine. In contrast, most legumes are rich in lysine but low in sulfur containing amino acids. Hence, the blends of cereals and pulses can complement their limited nutrients (MensaWilmot et al., 2004). The stable foods in developing country are mostly carbohydrate based cereal products and for the majority of the population it is difficult to afford high protein foods. Pasta is one of the highly consumed and affordable cereal based product (Chiari, 2014; Paola et al., 2015). Therefore, fortifying the durum wheat semolina with other nutritious cereal and legumes is important to improve the nutritional quality of pasta products specifically the dietary fiber, protein and mineral contents can be improved

Steglich (2013) identified three driving forces in which non-traditional ingredients used as supplements or substitute to durum wheat pasta as: increase the nutritional level, replace durum wheat with local available grain and decrease allergenicity specifically reduce or replace gluten. Accordingly, different studies done in order to address these issues include fortification with non-traditional ingredients such as legume flours for protein source (Petitot et al., 2010a); vegetable (tomato, spinach or carrot) for colouring (Cubadda, 1993), egg as supplemental for non-gluten pasta (Hager et al., 2013), cereal bran for important source of insoluble dietary fiber (Kaur et al., 2012) and commercial bran sources (inulin, pectin and others) for highly soluble fibers component (Robin et al., 2012).

Three reasons why partially or totally substitute durum wheat semolina with indigenous/commonly used cereals and legumes to produce pasta products: firstly economic and political purpose; secondly, improving the nutritional quality (protein, vitamin and mineral enrichment) and finally reducing allergenicity. Summarized review on the effects of non-traditional ingredients on the nutritional, heath and quality (sensorial and cooking) of the pasta formulated is presented in Table 2 . 
Table 2: List of non-traditional ingredients tested for nutritional profile, functional property, cooking and sensory quality of pasta.

\begin{tabular}{|c|c|c|c|}
\hline Category & Type & $\begin{array}{l}\text { Effects on nutritional, heath and quality (sensorial and } \\
\text { cooking) of the pasta formulated }\end{array}$ & References \\
\hline \multirow{21}{*}{ Legumes } & \multirow{6}{*}{ Chickpea } & Increased the mineral, fat and indigestible compound & \multirow{3}{*}{$\begin{array}{l}\text { Goni I. and } \\
\text { Valentin- } \\
\text { Gamazo, } \\
2003\end{array}$} \\
\hline & & $\begin{array}{l}\text { Lower glycaemic response/indices (GI) } \\
\text { (GI wheat spaghetti: } 73.5 \text {; GI wheat }+ \text { chickpea spaghetti: } \\
58.6 \text { ) }\end{array}$ & \\
\hline & & Lower starch hydrolysis & \\
\hline & & Lower in cooking loss and less stickiness & \multirow{3}{*}{$\begin{array}{l}\text { Wood, } \\
2009\end{array}$} \\
\hline & & Equal or better retained firmness & \\
\hline & & Increased the cooking time, water absorption and stiffness & \\
\hline & \multirow{2}{*}{ Chickpea $(5-15 \%)$} & $\begin{array}{l}\text { Improves the physical characteristics of dough; } \\
\text { optimum strength and extensible properties }\end{array}$ & \multirow{2}{*}{$\begin{array}{l}\text { Sabanis et } \\
\text { al., } 2006\end{array}$} \\
\hline & & $\begin{array}{l}\text { Meet the specification of pasta products in terms of firmness, } \\
\text { cooking quality and sensory evaluation. }\end{array}$ & \\
\hline & $\begin{array}{l}\text { Defatted soy }(10 \%) \\
\text { and Chickpea }(14 \%)\end{array}$ & $\begin{array}{l}\text { Better cooking and sensory quality } \\
\text { quality and nutritious pasta }\end{array}$ & $\begin{array}{l}\text { Bashir et } \\
\text { al., } 2012\end{array}$ \\
\hline & \multirow{4}{*}{$\begin{array}{l}\text { Green pea, yellow } \\
\text { pea, chickpea and } \\
\text { lentil }\end{array}$} & $\begin{array}{l}\text { Darken the spaghetti color and similar cooked weight to } \\
\text { control pasta }\end{array}$ & \multirow{4}{*}{$\begin{array}{l}\text { Zhao et al., } \\
2005\end{array}$} \\
\hline & & $\begin{array}{l}\text { Cooking loss and firmness increased with an increase in } \\
\text { legume flour content }\end{array}$ & \\
\hline & & $\begin{array}{l}\text { Firmness, flavor and color intensity of the pasta products } \\
\text { increased with the increase in legume flour fortification up to } \\
30 \%\end{array}$ & \\
\hline & & $\begin{array}{l}\text { The intensity of the shiny appearance, elasticity, and overall } \\
\text { quality decreased }\end{array}$ & \\
\hline & \multirow[t]{2}{*}{ Peanut } & High protein content and balanced amino acid (lysine) & \multirow{2}{*}{$\begin{array}{l}\text { Howard et } \\
\text { al., } 2011\end{array}$} \\
\hline & & Darker colour and higher cooking loss & \\
\hline & \multirow[t]{2}{*}{ Broad bean } & High protein and dietary fiber content & \multirow{2}{*}{$\begin{array}{l}\text { Giménez } \\
\text { et al., } 2012\end{array}$} \\
\hline & & Equal or similar cooking time & \\
\hline & \multirow{4}{*}{ Lupin } & Increase in protein and dietary fiber contents. & \multirow{4}{*}{$\begin{array}{l}\text { Jayasena } \\
\text { and Nasar- } \\
\text { abbas, } \\
2011\end{array}$} \\
\hline & & $\begin{array}{l}\text { Stickiness of cooked pasta decreased at } 30 \% \text { lupin flour } \\
\text { incorporation. }\end{array}$ & \\
\hline & & $\begin{array}{l}\text { No changes in firmness, color ( } L^{*} \text { and } b^{*} \text { values), appearance, } \\
\text { taste, texture and overall acceptability up to } 20 \% \text { lupin flour } \\
\text { incorporation }\end{array}$ & \\
\hline & & $\begin{array}{l}\text { Decrease in cooking time ( } 40 \text { and } 50 \% \text { lupin flour) and similar } \\
\text { property with lower portion to durum }\end{array}$ & \\
\hline \multirow{3}{*}{$\begin{array}{l}\text { Gluten } \\
\text { free } \\
\text { spaghetti }\end{array}$} & \multirow{3}{*}{$\begin{array}{l}\text { Unripe plantain, } \\
\text { chickpea and maize } \\
\text { flours }\end{array}$} & $\begin{array}{l}\text { Higher hardness, cohesiveness and chewiness in gluten free } \\
\text { spaghetti }\end{array}$ & \multirow{3}{*}{$\begin{array}{l}\text { Flores- } \\
\text { Silva et al., } \\
2015\end{array}$} \\
\hline & & $\begin{array}{l}\text { Lower elasticity; Lower maximum peak viscosity and high } \\
\text { setback viscosity }\end{array}$ & \\
\hline & & Similar overall sensorial acceptability & \\
\hline \multirow{2}{*}{$\begin{array}{l}\text { Plant } \\
\text { protein } \\
\text { sources }\end{array}$} & \multirow{2}{*}{$\begin{array}{l}\text { Mushroom }(8 \%), \\
\text { Bengal gram }(15 \%) \\
\text { and defatted soy }(9 \%)\end{array}$} & Better cooking and sensory quality and nutritious pasta & \multirow{2}{*}{$\begin{array}{l}\text { Kaur et al., } \\
2013\end{array}$} \\
\hline & & $\begin{array}{l}\text { Addition of defatted soy flour in semolina significantly } \\
\text { increased the cooking time of pasta }\end{array}$ & \\
\hline \multirow{10}{*}{ Cereal } & \multirow[t]{3}{*}{ Oat } & Higher levels of fiber and mineral composition & \multirow{3}{*}{$\begin{array}{l}\text { Hager et } \\
\text { al., } 2013\end{array}$} \\
\hline & & Similar sensory properties with durum wheat & \\
\hline & & Lower gluten index $<$ tef $<$ durum wheat & \\
\hline & \multirow[t]{3}{*}{ Tef } & Higher fiber content and mineral composition & \multirow{3}{*}{$\begin{array}{l}\text { Hager et } \\
\text { al., } 2013\end{array}$} \\
\hline & & Reduced sensory quality with durum wheat & \\
\hline & & Lower gluten index than durum wheat & \\
\hline & \multirow[t]{2}{*}{ Amaranthus } & Lower cooking time and dry breakage susceptibility & \multirow{2}{*}{$\begin{array}{l}\text { Chillo et } \\
\text { al., } 2008\end{array}$} \\
\hline & & Higher cooking loss and lower stickiness & \\
\hline & \multirow[t]{2}{*}{ Cereal bran } & Darker colour and lower cooking time & \multirow{2}{*}{$\begin{array}{l}\text { Kaur et al., } \\
2012\end{array}$} \\
\hline & & Highest protein and dietary fiber content with durum & \\
\hline
\end{tabular}




\section{Non-traditional cereals (tef) and legumes as potential fortification ingredients of pasta products Legumes}

Legumes are good sources of high-quality plant proteins among which chickpea (Cicer arietinum L.) is an important source of plant protein for human consumption. Chickpea is one of the important crops in developing countries agriculture as it is an alternative source of protein and source of micro-nutrients, cash income, and food security. It is also being utilized in crop rotation practices with major cereal crops like tef and wheat playing a significant role in restoring soil fertility by fixing atmospheric nitrogen..

There are two kinds of chickpea including kabuli and desi type which are distinguished by their seed size, shape, and colour and geographical distribution. Desi seeds grow in semi-arid tropics, while kabuli seeds grow in temperate regions. The kabuli types are large $(>0.3 \mathrm{~g})$, smooth surface, and cream colour whereas desi type chickpea are small $(0.1-0.3 \mathrm{~g})$, more angular shaped, wrinkled surface and dark, thick seed coat (Chavan et al.,1986; Wood et al., 2008). Due to their larger size and greater nutritional value, kabuli chickpeas are more popular for human consumption. The nutritional composition of kabuli type chickpea are protein $(17.8-27.5) \%$, fat $(4.5-5.7) \%$, carbohydrate $(56.7-63.0) \%$ and fiber $(4.0-8.0) \%$ whereas desi type are protein $22.9 \%$, fat $4.6 \%$, carbohydrate 46\% and fiber 24.6\% (Chavan et al., 1986; Wang et al., 2009; Kinfe et al.,2015).

Legumes are especially valuable in providing human diets with well-balanced amino acid composition when mixed with processed cereals. For instance, fortified spaghetti with legumes was reported to provide high protein and nutritious diet for low- income people and for people wishing to improve the nutritional quality of their diet (Bahnassey and Khan, 1986).

Therefore, because of their availability in Ethiopia, their nutritional and heath benefit and their some functional attributes indigenous cereal and legume flours were considered as potential candidates to formulate nutritionally enhanced and health promoting durum wheat based fortified pasta.

\section{Cereal (Tef)}

Tef (Eragrostis tef trotter) is originated in Ethiopia where is owes the major diversity and it is a staple crop. It is one of the most preferably cultivated grain by Ethiopian farmers as it has high market value (grain and straw) and it performs better under moisture stress and waterlogged conditions (Assefa et al., 2013). The grain can be stored long period for it is less susceptible for storage pests (Hailu and Seyfu, 2003). Traditionally, tef flour is widely used for making a fermented flat bread injera, traditional alcoholic beer (tella), local alcoholic drink or spirit (Arake or katikalla), sweet dry unleavened bread (kitta), gruel (muk)and porridge (genfo).

Bultosa and Taylor (2004) and Bultosa (2007) reported on physico-chemical composition of 13 tef varieties that tef grain was found with crude protein, crude fat and crude fiber contents ranged between $(8.7-11.1) \%,(2.0$ $3.0) \%$ and $(2.6-3.8) \%$, respectively.

Tef has an attractive nutritional profile and gluten free nature. This makes it suitable potential candidate to be used as ingredient in the formulation of new cereal based foods. Hence, it can be a substitute for wheat and other cereals in their food application and produces an alternative food product. Tef is being considered as a good option as functional food ingredient for gluten intolerant and celiac disease patients (Dekking et al., 2004, Hager et al., 2012b; Giuberti et al., 2015). In addition, it is proved that it can give possibility to manufacture as a novel food and ingredient such as gluten-free beer and energy cereal bars (Gebremariam et al.,2012); tef based breads, breakfast cereals and waffles (Laike et al., 2010; Tesfaye, 2000). It can also be used to make various kinds of recipe such as appetizers, brownies, cracker, desserts, pie crusts, cookies, cakes, pan cakes, muffins, pizza crusts, soups, tortillas and flat breads (Gamboa and Ekris, 2008; Dereje et al., 2015).

For instance, Sirawdink and Ramasway (2011) tried to formulate protein-rich extruded products from tef, corn and soybean protein isolate (SPI) and reported that 20\% tef, 60\% corn, and 20\% SPI gave extruded product with desirable attributes. The blend ratio with lower proportions of corn; higher proportion of tef and soybean protein isolates showed decreased colour value and higher levels of product hardness.

\section{Effect of durum wheat semolina replacement with non-traditional ingredient on pasta quality}

Pasta quality attributes are classified into seven categories: proximate composition, dough properties, drying properties, cooking properties, colour, mechanical properties, and sensory properties (Mercier et al., 2016). The proximate composition, cooking properties and colour are the quality attributes most frequently considered.

The incorporation of pulses into cereals provides an opportunity to use non-traditional raw materials to increase the nutritional quality of pasta. Introduction of pulse flour into pasta ultimately increases the protein, insoluble fiber, vitamin (B1, B5, B6 and B9) and mineral (Fe, Mg and P) contents, although it affects the ease of processing and quality attributes of pasta (Farooq and Boye, 2011).

\section{Effect of the non-traditional ingredients on nutritional, functional and phytochemical characteristics of the pasta}

Gluten forming proteins are primarily responsible for the functional properties of wheat flour. The amount of 
gluten in flour is an index of the protein content and physical properties of the washed out gluten (i.e. index of flour strength). Wet gluten and dry gluten criteria are as a primary test of flour quality. This is likely due to the simplicity of the test and the quantitative information obtained relating to both gluten content and quality. Semolina wet gluten is highly correlated to the protein content which is the most desired quality test parameter (Chinnaswamy et al., 2005).

In the revised Codex Alimentarius standard (1998), a limit of gluten in product made only from naturally gluten-free ingredients is $20 \mathrm{ppm}$ while only for foods containing a mixture of the two ingredients is $200 \mathrm{ppm}$. The average gluten-containing diet contains roughly 10-40 grams of gluten per day.

The gluten index method provides information on both quantity and quality of wet gluten. Gluten index value is a criterion defining whether the gluten quality is weak, strong or normal. Based on GI values, Cubadda et al. (1993) proposed seven gluten quality classes in durum wheat, GI values between 65 and 80 are considered good, while values above 80 are excellent. With this regard chickpea based pasta has decreased glycemic response level from glycemic index (GI) 73.5 to 58.6 compared with durum wheat pasta or control samples (Goni and ValentinGamazo, 2003).

Pulses are rich in essential amino acids, including lysine, threonine, isoleucine, leucine, phenylalanine and valine, and have a good mineral profile, containing $\mathrm{K}, \mathrm{Fe}, \mathrm{Cu}, \mathrm{Mg}, \mathrm{Zn}$ and $\mathrm{Mn}$. In contrast, cereals are deficient in certain essential amino acids and also lose some of their mineral content when milled, owing to the removal of the aleurone layer, which is a rich source of minerals. To improve their amino acid profile and mineral complementarily, cereals may be fortified with pulses. Ensuring an optimal level of fortification requires studying the characteristics of flour and semolina, especially their particle size and composition, for acceptable product development (Farooq and Boye, 2011). Legume-fortified cereals therefore offer a broader spectrum for those who wish to improve the nutritional quality of their diet.

The chemical composition of semolina and legume flours also determines the nature and level of fortification. Lentil, dry pea, chickpea, field pea and dry bean are considered foods of great nutritional value and are also important sources of dietary fiber, an essential part of a healthy diet. Dietary fiber not only naturally promotes bowel health but also helps to lower cholesterol, balances blood glucose, and promotes healthy physiology and well-being (Padalino et al., 2011).

Hence, replacing cereals with high protein legumes is one of the recommended solutions to protein-energy malnutrition, particularly in developing countries (Singh, 2001). Because chickpea contains higher content essential amino acid and combined with cereals that increased the protein content (Wesche-Ebeling et al., 2001). Blending navy bean and pinto bean protein isolates with semolina produced spaghetti with high protein and lysine contents (Seyam et al., 1983). Wood (2009) reported that incorporated chickpea flour (0-30)\% into durum wheat semolina and with the increasing amount of chickpea flour total protein and all the amino acids amount increased. Moreover, with increased chickpea amount the mineral, fat and indigestible compound content increased; while starch hydrolysis of the pasta was lowered (Goni and Valentin-Gamazo, 2003; Besher et al., 2012).

Enrichment affects the protein and fiber content of pasta. Mercier et al.(2016) review exhibited that the enrichment of pasta with pulse flour increased the protein content by an average of $1.8 \pm 0.5 \mathrm{~g} /(100 \mathrm{~g}$ dry pasta $)$ with the control pasta and for enrichment levels below $15 \%$ and by an average of $4.0 \pm 1.0 \mathrm{~g} /(100 \mathrm{~g}$ dry pasta $)$ for higher enrichment levels. An increased consumption of dietary fiber in daily diet has been recommended by nutritionists to improve health. But during durum wheat milling process, the semolina is extracted from germ and bran (good source fiber) of the grain.

As a result pasta products are very low in dietary fiber contents, a number of studies have conducted aimed at increasing the dietary fiber contents. Jayasena and Nasar-Abbas (2011) reported that total dietary fiber in pasta enriched with $50 \mathrm{~g} / 100 \mathrm{~g}$ lupin kernel fiber increased from 1.5 to $15 \%$. Addition legume flours such as soy flour (Shogren et al., 2006), quinoa, broad bean and chickpea flours (Chillo et al. 2008) when added to semolina to produce pasta could improve mainly protein contents but less impact on the dietary fiber contents. The addition of tef flour improved the dietary fiber content that provides beneficial effects on human health (Bultosa, 2007; Baye, 2014).

However, the quality of the fortified pasta products depends on the chickpea amount. Fortification of pasta with chickpea flour above $30 \%$ was not possible because of particle aggregation. This renders the feeding of the extrusion screw and difficult during mixing and weakening of the gluten matrix (Wood, 2009). Wang et al (2010) reported that increase the resistant starch content in chickpea increases in soluble dietary fiber. The presence of fiber causes a physical disruption of the gluten matrix, which may facilitate the penetration of water to the core of the pasta.

Study made by Hager et al. (2012a and 2013) shown gluten free egg based spaghetti was made from tef flour and the product was compared with that of oat and wheat based products. Tef based pasta are nutritionally superior to wheat in terms of fiber and mineral content. Besides, tef spaghetti had a lower predicted glycemic index (pGI) (45) than wheat spaghetti (67), and the pGI was higher than that of oat spaghetti (32). Similarly, Giuberti et al. (2015) evaluated the effect of partial substitution of tef up to $40 \%$ with common bean flour at different 
incorporation rates to produce gluten free "tagliatelle". The bean flour addition increased the dietary fiber and protein contents while decreasing the starch content and showed significant impact on cooking and sensory quality. The bean flour addition greatly increased the resistant starch content and reduced the GI from 60 to 39.

Phytates are the primary form of phosphorus storage in seeds which accounts for $60-90 \%$ of the total phosphorus and a common constituent of cereals and legumes (Schlemmer et al., 2009). Tef contains high amounts of phytate with a wide range of variability, probably due to differences in processing condition, varieties and growing conditions and likely to weaken the absorption of iron and zinc (Schlemmer et al., 2009; Baye, 2014). The phytate interfere iron and zinc absorption in the gastrointestinal tract with the formation of insoluble phytatemineral complexes (Manary et al., 2002; Weaver and Kannan, 2002).

Traditional processing technologies (decortications, soaking, germination and fermentation) and extrusion technology are commonly applied to reduce the levels of antinutritional factors (trypsin inhibitor, tannins and phytates), denatures undesirable enzymes and retains natural colours and flavours of foods (Guy, 2001). But traditional processing technologies are limited by their laborious and time demanding nature.

\section{Effect of the non-traditional ingredients on texture and cooking properties of pasta}

The competences of gluten to form a protein network have an impact on cooking quality and textural properties of durum wheat pasta. Durum wheat proteins are composed mainly of glutenin and gliadins that form intra- and intermolecular disulfide bonds during processing. This phenomenon leads to the formation of a three-dimensional gluten network responsible for the unique textural properties of pasta (Farooq and Boye, 2011). But pulse proteins are composed mainly of salt-soluble globulins and water-soluble albumins. The addition of non-gluten material dilutes the gluten strength and likely weakens the overall structure of the pasta. As a consequence, more solids leach from the pasta into the cooking water (Rayas-Duarte et al., 1996).

Effects of incorporation of legumes (like lupin, soybean; navy and pinto protein isolates) in durum wheat based pasta used for making pasta products are reported by Morad et al. (1980) and Seyam et al.(1983). The studies showed that increasing level of soybean flour (2-6)\% in macaroni with increased cooked weight (Morad et al.1980). However, the same study showed that increasing the level of soybean flour decreased cooking quality and imparted undesirable grayish color. The increasing level of lupin flour (2-6)\% with increased cooked weight, increased cooking quality and enhanced natural amber color of the lupin which is a desirable color in macaroni (Morad et al., 1980). The formulation of spaghetti by blending navy bean and protein isolates of pinto bean with semolina gave inferior colour, low cooked weight and high cooking loss compared with 100\% durum wheat pasta (Seyam et al., 1983).

Similarly, substituting split pea or faba bean flour and chickpea flour for durum wheat semolina at a high level $(35 \%)$ requires adapting the pasta-making process at the pilot scale and has a noticeable impact on the cooking quality of pasta, decreasing the optimal cooking time for low temperature dried pasta and resulting in lower water uptake and higher cooking losses (Wood, 2009; Petitot et al., 2010).

Fortification with legume flours such as navy bean, pinto bean, lentil or green pea protein concentrates causes an increase in firmness, which represents the cutting force required to penetrate product strands compared with 100\% durum wheat pasta (Seyam et al., 1983, Bahnassey and Khan, 1986; Zhao et al., 2005).

Wood (2009) reported that increasing chickpea flour (0-30)\% into durum wheat semolina to produce spaghetti reduced firmness, improved stickiness and reduced cooking loss of the pasta product. The spaghetti samples supplemented with $15 \%$ pea flour showed less elasticity, unpleasant colour and higher firmness compared to the control sample (Padalino et al., 2014).

Hager et al.(2012a) studied the formulation of egg pasta from wheat, oat and tef flours. The study indicated the optimum response surface methodology (RSM) level of $62.8 \%$ tef flour, $25.1 \%$ water, $11 \%$ egg white powder and $1.1 \%$ emulsifier produced gluten free pasta with acceptable texture but with lower stickiness and less elasticity. Similarly, Giuberti et al.(2015) study on the partial substitute of tef with bean flour to produce gluten free "tagliatelle" or pasta. The texture of tef tagliatelle was not affected by the bean flour addition. The increment on the replacement of bean to tef flour from $(0$ to 40$) \%$ showed the tagliatelle product has increased optimal cooking time, similar cooking loss effect and colour variation. The texture of spaghetti produced from tef and oat was similar to that of wheat spaghetti except for the lower elasticity.

\section{Effect of the non-traditional ingredients on sensorial quality of pasta}

The main sensory attributes of the pasta are appearance, flavour, texture and overall acceptability. Product colour is one of the main critical parameters affecting the appearance and overall acceptability of pasta. The yellowish colour of pasta is mainly due to the degradation of carotenoid pigments in semolina. This pigment degradation is caused by lipoxygenase and manufacturing process (Fua et al., 2013). Generally, consumers prefer a bright yellow colour, but fortification with pulse flour significantly decreases brightness because of the higher ash content of legume flours, especially green pea, chickpea, lentil and faba bean flours (Wood, 2009).

The external appearance of pasta and other attributes of sensory quality after cooking are the most important 
criteria of pasta quality evaluation. The appearance assessment includes: colour, specks, surface discoloration and texture (smoothness, white spots, streaks, air bubbles) (Feillet et al., 2000). Pasta and noodles fortified with lupin or chickpea flour up to a $10 \%$ substitution level are generally well accepted, and there appears to be no impact on appearance, taste or texture at higher substitution levels (Zhao et al., 2005; Sabanis et al., 2006).

The spaghetti samples supplemented with $15 \%$ pea flour into semolina improved the overall sensory quality compared to the control sample (Padalino et al., 2014). Additionally, the inclusion of (5-10)\% chickpea flour in pasta products improved organoleptic properties (such as colour and flavour) and met the pasta quality criteria in terms of firmness and cooking quality (Sabanis et al., 2006). According to Hager et al.(2012a and 2013), tef based spaghetti was inferior overall sensory acceptance compared with wheat and oat spaghetti.

\section{Conclusion and recommendation}

Legumes and cereals fortified pasta for consumers have strong desire to improve the nutritional quality and healthy diet. In this review, there have been a lot of interesting findings and insights for developing countries where they have adequate recipe developments from their indigenous or local grains which are an important portion of substitution of wheat grain.

The fortification of pasta with crops had a noticeable effect on the functional, nutritional, cooking and textural quality of pasta. The review of this study clearly demonstrate that fortified pasta had superior nutritional qualities to spaghetti/macaroni/ noodle made from 100\% durum semolina, confirming the better nutritional balance of legume-cereal blends. Additionally, highly sensorial acceptable pasta products (colour, appearance, taste, flavour and texture) could be prepared by incorporating durum wheat semolina with composite of legume-cereal blends. can be formulated. Still much effort is needed to find the processing effects and the optimization of legume and cereals flour used for pasta products by identifying and mixing different local crop flours to maximize the composite pasta quality using the mixture response surface methodology.

\section{References}

Bahnassey, Y. and Khan, K. (1986). Fortification of spaghetti with edible legumes. II. Rheological, processing, and quality evaluation studies. Cereal chemistry, 63, 216-219.

Barrelli, G.M, Troccoli, A. Difonzo, N. and Fares, C. (1999). Durum wheat Lipoxygenase activity, and other quality parameters that affect pasta colour. Cereal Chemistry, 76, $335-340$.

Bashir K., Aeri V., and Masoodi, L. (2012). Physio-Chemical and Sensory Characteristics of Pasta Fortified With Chickpea Flour and Defatted Soy Flour. Journal of Environmental Science, Toxicology And Food Technology (IOSR-JESTFT), 1(5), 34-39

Bultosa, G. (2007). Physicochemical Characteristics of Grain and Flour in 13 Tef [Eragrostis tef (Zucc.)Trotter] Grain Varieties. Journal of Applied Science Research, 3, 2042-2051.

Bultosa, G. and Taylor, J.R.N. (2004). Tef. In: Wrigley, C., Corke, H., \& Walker C. (eds.). Encyclopedia of grain science, 3, 281 -290, Elsevier Ltd. pp.

Chavan, J., Kadan, S. and Salunkhe, D. (1986). Biochemistry and technology of chickpea (Cicer arietinum L.) seeds. Critical Review on Food Science and Nutrition, 25-107.

Chiari, T. (2014). Reports on the Ethiopian pasta is booming production. Professional pasta. Trade. Italian Coordinator of "Agricultural Value Chains Project in Oromia (Avcpo). Ministry of Foreign Affairs and International Cooperation.

Chillo, S., Laverse, J., Falcone, P. M. and Del Nobile, M. A. (2008). Quality of spaghetti in base amaranthus whole meal flour added with quinoa, broad bean and chickpea. Journal of Food Engineering, 84, 101-107

Codex Alimentarius standard (CAC), (2006). Standard for gluten free products (Codex standard A -2-19 73.

Cubadda, R. (1993). Nutritional value of pasta. Effects of processing conditions. Italian Food Beverage Technology, 3, 27-33.

Dekking, S. L., Kooy-Winkelaar, Y. and Koning F. (2005). The Ethiopian Cereal Tef in Celiac Disease. New England Journal of Medicine, 353, 1748-1749.

Dereje, F., Solomon, A., Tamirat, K., Bilatu, A., Gelila, A. and Legesse, S. (2015). Nutrition of Tef (Eragrostis tef) Recipes. Food Science and Quality Management. Vol. 45.

Dexter, J.E. and Marchylo, B.A. (2000). Recent trends in durum wheat milling and pasta processing: Impact on durum wheat quality requirements. Pages 77-101 in: Proc. International workshop on durum wheat, semolina and pasta quality: Recent achievements and new trends, November 27, 2000.

Dexter, J.E., Symons, S.J. and Martin, D.G. (1994). Enhancement of durum wheat milling quality by preprocessing and an evaluation of fluorescence. Imaging as a rapid technique for monitoring preprocessing efficiency. Association Operative Millers Bulletin, 64156420

Dick, J.W. and Matsuo, R. R. (1988). Durum wheat and pasta products. In: Y. Pomeranz (Ed.), Wheat: chemistry and technology (3rd ed.), 2, 507-547. American Association of Cereal Chemists: St. Paul, MN, USA

Douglass, J.S. and Matthews, R. H. (1982). Nutrient content of pasta products. Cereal Foods World, 27, 558-561. 
http://www.pasta.unfpa.org.

Drake, D.L., Gebhardt, S.E. and Malthews, R.H. (1989). Composition of foods. Cereal grains and pasta. US. Department of Agriculture Mormon nutrition information service. Agricultural Handbook, 8 - 20, OSU DisClaimer URL Home: Food Resource \{http://foodoregonstate.edu/\} g/comp/compasta.html

Feillet, P. and Dexter, J.E. (1996). Quality requirements of durum wheat for semolina milling and pasta production. In: J.E. Kruger, R.R. Matsuo and J.W. Dick, Editors, Pasta and noodle technology, American Association of Cereal Chemists, St. Paul, MN, USA, 95- 131.

Feillet, P., Autran, J.C. and Icard-Vernière, Ch. (2000). Pasta brownness: an assessment. Journal Cereal Science, $32,215-233$.

Ferrari, L. and Piazza, N. (2006). Nutritional value of pasta. Professional Pasta Newsletter, 31, 40-44.

Flores-Silva P C., Berrios J D., Pan J., Agama-Acevedo E., Monsalve-González A., and Bello-Pérez Luis A.( 2015). Gluten-free spaghetti with unripe plantain, chickpea and maize: physicochemical, texture and sensory properties. Journal of Food (CyTA ) 13 (2) 159-166, http://dx.doi.org/10.1080/19476337.2014.929178.

Fua, B.X., Schlichtinga, L., Pozniak, C.J. and Singh, A.K. (2013). Pigment loss from semolina to dough: Rapid measurement and relationship with pasta color. Journal of Cereal Science, 57, 560-566.

Fuad, T. and Prabhasankar, P. (2010). Role of Ingredients in Pasta Product Quality: A Review on Recent Developments, Critical Reviews in Food Science and Nutrition, 50 (8), 787-798.

Gamboa, P. and Ekris, L. (2008). Tef: survey on the nutritional and health aspects of tef (Eragrostis tef). http://educon.javeriana.edu.co/lagrotech/images/patricia_arguedas.

Gebremariam, M.M., Zarnkow, M. and Becker, T. (2012). Tef (Eragrostis tef) as a raw material for malting, brewing and manufacturing of gluten-free foods and beverages: a review. Journal of Food Science and Technology

Giménez, M.A., Drago, S.R., De Greef, D., Gonzalez, R.J., Lobo, M.O. and Samman, N.C. (2012). Rheological, functional and nutritional properties of wheat/broad bean (Vicia faba) flour blends for pasta formulation. Journal of Food Chemistry, 134, 200-206.

Giuberti, G., Gallo, A., Fiorentini, L., Fortunati, P. and Masoero, F. (2015). In vitro starch digestibility and quality attributes of gluten free "tagliatelle" prepared with tef flour and increasing levels of a new developed bean cultivar. Short communication. doi: [10.1002/star.201500007].

Goni I. and Valentin-Gamazo C (2003). Chickpea flour ingredient slows glycemic response to pasta in healthy volunteers. Journal of Food Chemistry 81: 511-515

Guarda, A., Rosell, M., Benedito, C. and Galotto, J. (2004). Different hydrocolloids as bread improvers and antistaling agents. Food Hydrocolloids, 18, 241-247.

Hager, A., Czerny, M., Bez, J., Zannini, E. and Arendt, E. (2013). Starch properties, in vitro digestibility and sensory evaluation of fresh egg pasta produced from oat, tef and wheat flour. Journal of Cereal Science, 58, $156-163$.

Hager, A., Wolter, A., Jacob, F., Zannini, E., and Arendt, K. (2012a). Nutritional properties and ultra-structure of commercial gluten free flours from different botanical sources compared to wheat flours. Journal of Cereal Science, 56, 239-247.

Hager, A., Lauck, F., Zannin, E. and Arendt, E. (2012b). Development of gluten-free fresh egg pasta based on oat and tef flour. European Food Research Technology. DOI 10.1007/s00217-012-1813-9.

Hailu, T. and Seyfu, K. (2003). Tef genetic resources in Ethiopia. In: Hailu Tefera, Getachew Belay and Mark Sorrells (edition.). Narrowing the Rift. Tef Research and Development. Proceedings of the International Workshop on Tef Genetics and Improvement, DebreZeit, Ethiopia, p 27-31.

Howard, B., Hung, Y. and McWatters, K. (2011). Analysis of ingredient functionality and formulation optimization of pasta supplemented with peanut Flour. Journal of Food Science, 76, E40- E47.

Jayasena, V. and Nasar-Abbas, S. (2011). Development and quality evaluation of high-protein and high-dietaryfiber past a using lupin flour. Journal of Texture Studies, 43, 153-163.

Kaur, G., Sharma, S., Nagi, H., and Dar, H. (2012). Functional properties of pasta enriched with variable cereal brans. Journal of Food Science and Technology, 49, 467-474.

Kaur G., Sharma S., Nagi P. S. and Ranote P. S. (2013) Enrichment of pasta with different plant proteins. Journal of Food Science and Technology 50(5):1000-1005.

Kinfe, E., Pragya, S. and Tigist, F., (2015). Physicochemical and Functional Characteristics of Desi and Kabuli Chickpea (Cicer arietinum L.) Cultivars Grown in Bodity, Ethiopia and Sensory Evaluation of Boiled and Roasted Products Prepared Using Chickpea Varieties. International Journal of Current Research Bioscience Plant Biology, 2, 21-29.

Kruger, J., Matsuo, R. and Dick, J. (1996). Pasta and Noodle Technology. St. Paul: American Association of Cereal Chemists: $356 \mathrm{p}$.

Laike, K., Solomon, W., Geremew, B. and Senayit, Y., (2010). Effect of extrusion operating conditions on the 
physical and sensory properties of tef (Eragrostis tef [Zucc.] Trotter) flour extrudates. Ethiopian Journal of Applied Science Technology, 1, 27-38.

Liu, Y., Shepherd, W. and Rathjen, J. (1996). Improvement of durum wheat pasta making and bread making qualities. Cereal Chemistry, 73, 155-166.

Matsuo, R.R., and Dexter, J.E. (1980). Comparison of experimentally milled durum wheat semolina to semolina produced by some Canadian commercial mills. Cereal Chemistry, 57,117-122.

Melissa, S. (2014). Fortification of pasta with chickpea and quinoa flours.

Mensa-Wilmot, Phillips, R. D., Lee, J. and Eitenmiller, R. R. (2004). Formulation and evaluation of cereal/ legume-based weaning food supplements. Plant Foods for Human Nutrition, 58, 1-14.

Mercier, S., Moresoli, C., Mondor, M., Villeneuve, S. and Marcos, B. (2016). A Meta-analysis of enriched pasta: What are the effects of enrichment and process specifications on the quality attributes of pasta? Comprehensive Reviews in Food Science and Food Safety, 15, 685-704.

Robin, F., Schuchmann, H. and Palzer, S. (2012). Dietary fiber in extruded cereals: Limitations and opportunities. Trends in Food Science and Technology, 28, 23-32.

Padalino, L., Mastromatteo, M., Lecce, L., Spinelli, S., Conto, F. and Del Nobile, M. A. (2014). Chemical composition, sensory and cooking quality evaluation of durum wheat spaghetti enriched with pea flour. International Journal of Food Science and Technology 49, 1544- 1556.

Pagini, A. (1986). Pasta products from non-conventional raw materials. In: Pasta and Extrusion Cooked Foods. Mercier, C. and Cantarelli, C. eds. Elsevier Applied Science: London

Paola, F., Roberto, R. and Silvia, F. (2015). Raw materials for the production of functional pasta. Open Fields.

Petitot, M., Boyer, L., Minier, C. and Micard, V. (2010). Fortification of pasta with split pea and faba bean flours: pasta processing and quality evaluation. Food Research International, 43, 634-641.

Sabanis, D., Makri, E. and Doxastakis, G., (2006). Effect of Durum flour enrichment with chickpea flour on the characteristics of dough and lasagna. Journal of the Science of Food and Agriculture, 86, 1938-1944.

Sirawdink, F. and Ramaswamy, H. (2011). Protein rich extruded products from tef, corn and soy protein isolate blends. Ethiopian Journal Applied Science and Technology, 2, 75 - 90.

Starta, A. (2004). Nutritional values of pasta. Chair of food science and dietetics faculty of medicine and surgery. Paroma University. http://www.profissionalpasta.it-1nutritional-1.htm

Steglich, T. (2013). Pasta as an example for structure and dynamics of carbohydrate rich food materials. Swedish Institute for Food and Biotechnology (SIK) Report 849. Göteborg.

Tesfaye, T. (2000). An overview of tef and durum wheat production in Ethiopia. Ethiopia: Ministry of Agriculture \& Rural Development.

U.S. Department of Agriculture, Agricultural Research Service (2016). USDA national nutrient database for standard reference, release 28. Nutrient data laboratory home page. The National Agricultural Library. http:// ndb.nal.usda.gov/ndb/search

Wang, X., Gao, W., Zhang, J., Zhang, H., Li, J., He, X. and Ma, H. (2009). Subunit, amino acid composition and in vitro digestibility of protein isolates from Chinese kabuli and desi chickpea (Cicer arietinum L.) cultivars. Food Research International.

Wood, J., Knights, E. and Harden, S. (2008). Milling performance in desi - type chickpea (Cicer arietinum L.): effects of genotype, environment and seed size. Journal of the Science Food and Agriculture, 88, 108-115.

Wood, J. (2009). Texture, processing and organoleptic properties of chickpea fortified spaghetti with insights to the underlying mechanisms of traditional durum pasta quality. Journal of cereal science, 49, 128-133.

1Zhao Y H., Manthey F A., Chang S K.C., Home-Jer H, and Yuan S. (2005). Quality Characteristics of Spaghetti as Affected by Green and Yellow Pea, Lentil, and Chickpea Flours. Journal of Food science 70 (6), 371-376 